\title{
AFECCIONES CORPORALES EN UNA PLANTA DE PRODUCCIÓN DE MATERIALES EDUCATIVOS
}

\author{
Teresita Ospina Álvarez (Universidad de San Buenaventura)* \\ https://orcid.org/0000-0002-7725-491X \\ Edilberto Hernández González (Universidad de San Buenaventura)** \\ https://orcid.org/0000-0002-6274-4078 \\ Cynthia Farina (IFSul- Brasil)*** \\ https://orcid.org/0000-0002-3732-9032
}

\section{RESUMEN}

Este artículo es derivado de la investigación Cartografías de una educación (otras), cuyos propósitos estuvieron dirigidos a recorrer lo educativo que sucede en los intersticios espaciales, temporales y corporales en una planta de producción de materiales educativos de Medellín. En esta se empleó un método cartográfico, con el cual fue posible mapear e indagar la experiencia de formación de los cuerpos, para ello se desarrollaron acciones, formas de registro y creación de nuevos pensamientos. Se encontró que la educación (otras) está vinculada a la construcción de una subjetividad que se teje a partir de un acontecimiento intenso que hace posible dar giros a la existencia y produce invenciones para lidiar con las experiencias de dolor: muertes violentas que cambian la vida, confrontan y obligan a potenciar fuerzas para continuar viviendo. Se percibió también, que junto a un gran dolor o el padecer hambre, se va superponiendo una capa sutil que espera el momento indicado para impulsar a una nueva vida y crear formas genuinas (singulares), de sobreponerse a las adversidades; es así, que la formación se ve agenciada por acontecimientos que fijan sus raíces en el cuerpo, pues en este acontece y, entra a circular por una cotidianidad compartida. Palabras clave: Afecciones. Cartografía. Educación (otras). Acontecimiento. Cuerpo.

* Doctora en Educación de la Universidad de Antioquia. Profesora del Doctorado en Ciencias de la Educación de la Universidad San Buenaventura, Medellín. Investigadora de la línea: Estudios culturales y Lenguajes Contemporáneos. Grupo de Investigación ESINED. E-mail: teresita.ospina@usbmed.edu.co

** Doctor en Educación de la Universidad de la Salle, CR. Profesor del Doctorado en Ciencias de la Educación de la Universidad San Buenaventura, Medellín (Colômbia). Investigador de la línea: Estudios culturales y Lenguajes Contemporáneos. Grupo de Investigación ESINED. E-mail: edilberto.hernandez@usbmed.edu.co

*** Postdoctora en Educación de la Pontifícia Universidade Católica do Rio Grande do Sul (PUC/RS). Doctora en Educación de la Universidad de Barcelona (UB, España). Professora del Instituto Federal de Educação, Ciência e Tecnologia Sul-riograndense (IFSul), Brasil. Línea de investigación Educación, Arte y Filosofía. E-mail: cynthiafarina@pelotas.ifsul.edu.br 


\section{ABSTRACT}

\section{BODY AFFECTIONS IN A PRODUCTION PLANT FOR EDUCATIONAL MATERIALS}

This article is derived from the research Cartographies of an education (others), whose purposes were aimed at exploring the educational that happens in the spatial, temporal and bodily interstices in a production plant of educational materials in Medellín. In this, a cartographic method was used, with which it was possible to map and investigate the experience of body formation; for this purpose, actions, forms of registration and creation of new thoughts were developed. It was found that education (others) is linked to the construction of a subjectivity that is woven from an intense event that makes it possible to turn around the existence and produces inventions to deal with pain experiences: violent deaths that change life, confront and force to strengthen forces to continue living. It was also perceived that, along with significant pain or suffering from hunger, a subtle layer starts to overlap awaiting the right moment to propel a new life and create genuine (singular) ways of overcoming adversity; thus, the formation is organized by events that fix their roots in the body, because in it happens and, it enters to circle through a shared daily life.

Keywords: Affections. Cartography. Education (others). Occurrence. Body.

\section{RESUMO}

\section{AFEIÇÕES CORPORAIS EM UMA PLANTA DE PRODUÇÃO DE MATERIAIS EDUCATIVOS}

Este artigo é derivado da pesquisa Cartografias de uma educação (outras), cujos objetivos foram explorar a educação que ocorre nos interstícios espaciais, temporais e corporais em uma planta de produção de materiais educativos em Medellín. Nesse sentido, foi utilizado um método cartográfico, com o qual foi possível mapear e investigar a experiência da formação do corpo. Para esse fim foram desenvolvidas ações, formas de registro e criação de novos pensamentos. Verificou-se que a educação (outros) está ligada à construção de uma subjetividade tecida a partir de um evento intenso que possibilita a volta à existência e produz invenções para lidar com as experiências de dor: mortes violentas que mudam a vida, confrontam e obrigam a inventar forças para continuar vivendo. Percebeu-se também que, juntamente com muita dor ou fome, sobrepõe-se uma camada sutil que aguarda o momento certo para impulsionar uma nova vida e criar maneiras genuínas (singulares) de superar as adversidades. Assim, a formação é organizada por eventos que fixam suas raízes no corpo, pois, com isso, acontece e entra no cotidiano compartilhado.

Palavras-chave: Afeições. Cartografía. Educação (outras). Evento. Corpo. 


\section{Introducción}

Los afectos piden paisajes. (ROLNIK, 1989).

El presente artículo se deriva de la investigación Cartografías de una educación (otras), ${ }^{1}$ la cual fue apoyada por la convocatoria de investigación de la Universidad de San Buenaventura, Medellín, y desarrollada del año 2017 al 2019, $\mathrm{y}$, cuyos intereses investigativos estuvieron dirigidos a recorrer lo educativo que sucede en los intersticios de las arquitecturas espaciales, temporales y corporales de un grupo de veinte personas que se desempeñan como operarias(os), en una planta de producción de materiales educativos, ubicada en el Área Metropolitana de Medellín, Colombia. Investigación que nos significó encontrar lugares por fuera de los espacios y discursos educativos, tradicional e institucionalmente constituidos, en los cuales la mirada permanece centrada en la transmisión y apropiación del conocimiento académico. Cartografiar una educación (otras), implicó encontrar maneras singulares de proceder en términos epistemológicos y concebir teóricamente lo educativo, en tanto experiencia corporal del transcurrir de los cuerpos en los espacios en una planta de producción.

En este sentido, en la filosofía de Deleuze encontramos unas pistas para movilizar las ideas hegemónicas sobre el cuerpo en el ámbito educativo, ideas que tienen que ver con la representación instaurada a partir del establecimiento de un modelo de cuerpo a seguir; de unas maneras de estar; de una producción de cuerpos homogéneos, disciplinados y obedientes; y, en consecuencia, la exclusión de la diferencia. Así, encontramos en el pensamiento de Deleuze, un cuerpo que deviene fuerzas y maneras de aparecer por fuera de las instituciones catalogadas

1 Investigación que es parte de los procesos de conceptualización y experimentación-creación desarrollados por la línea en Estudios culturales y lenguajes contemporáneos, del grupo de investigación ESINED, Universidad de San Buenaventura, Medellín; con la participación del grupo de investigación en Educación, Arte y Filosofía: Experimentaciones con arte y filosofía del Instituto Federal de Educação, Ciência e Tecnologia Sul-rio-grandense (IFSul), Pelotas, Brasil. como educativas; justamente, este cuerpo potencia, nos mueve a pensar la educación misma más allá de la institución educativa.

Si bien, Deleuze poco escribió sobre educación, nos permitió percibir la potencia que hay en conceptos como multiplicidad, intensidad, afección y cuerpo maquínico, para diagramar una educación (otra); perspectiva, que se aúna a la creación de otras líneas de trabajo en torno del pensamiento deleuziano, relacionadas con la "pedagogía del concepto, pedagogía como ciencia menor y pedagogía de la percepción" (SANDERS, 2011, p. 454).

En este orden, nos interesa una educación (otra), en términos de la formación del sujeto contemporáneo, de allí que nos interroguemos por aquello que tienen por decirnos unos cuerpos inmersos en una planta de producción, más aun, una planta de producción de los materiales que luego circularán por la escuela, es decir, parte de la materia que produce la escuela misma. Esto nos condujo a pensar en procesos formativos por fuera de la institucionalidad escolar, para prestar atención a lo educativo que acontece en la cotidianidad. Tal como lo plantea Farina (2005, p. 7)

Las maneras y las formas con las cuales entender la formación como no sólo aquello que se lleva a cabo en las escuelas e instituciones de enseñanza, si no aquello que configura las maneras como nos relacionamos cotidianamente con nosotros mismos. Los procesos de formación conciernen a cada individuo y, a la vez, nos sitúan como fenómeno colectivo. En estos procesos se genera un conjunto de maneras no solo de hacer, si no de entender las cosas en nuestra vida cotidiana, se genera nuestra propia experiencia.

Ocuparnos de la manera cómo sucede la producción de subjetividades en las acciones cotidianas, era entender que la educación puede acontecer por fuera de la escuela, lo que significa, entonces que esta estaría presente en el transcurrir de la experiencia del trabajar, conversar, habitar, como lo ha planteado Michel De Certeau (2000); de manera que la preocupación por las afecciones corporales en una planta de producción, está vinculada a la idea 
de un cuerpo que significa, que se-silencia, que expresa, que siente, que se-potencia, que vibra, que se-mueve; un cuerpo cargado de fuerzas, de experiencias, de presencias; un cuerpo que se hace singular y heterogéneo en cada encuentro - encuentros que fuimos comprendiendo que son siempre, educativos - y que en algunos casos ha sido desplazado por la idea de cuerpo mecánico o físico; restándole con ello, vida y potencia. Pensar los cuerpos en tanto experiencia-educativa, implicó problematizar aquella mirada utilitarista que pretende educar o capacitar, lo que supone la necesidad del adiestramiento y del desarrollo físico; asunto del cual se ocupó ampliamente Michel Foucault en Vigilar y Castigar (FOUCAULT, 2002) libro donde el autor profundiza en los mecanismos de adoctrinamiento, corrección e higienización que revelan el ejercicio de un poder disciplinado, el control y la vigilancia que, tanto otras instituciones, al igual que la escuela, ejercía y de hecho continúan ejerciendo sobre los cuerpos, en ese texto Foucault (2002, p. 144), resalta los cambios que se efectuados a partir de 1762 , entre ellos, qu

Al asignar lugares individuales, ha hecho posible el control de cada cual y el trabajo simultáneo de todos. Ha organizado una nueva economía del tiempo de aprendizaje. Ha hecho funcionar el espacio escolar como una máquina de aprender, pero también de vigilar, de jerarquizar, de recompensar.

Esas maneras de distribución de los espacios, el control de los tiempos, la regulación de las formas de sentarse, de disponerse en orden, las filas, los hábitos higiénicos y la rectitud corporal, no han dejado - en gran medida - de constituir la normalidad y el deber ser de los cuerpos en la educación de nuestros contextos.

Nietzsche (2017), Foucault (2002), Deleuze e Guattari (2012), entre otros autores, sostuvieron un pensamiento influyente en la crítica a las estructuras y discursos que reducían los cuerpos a fenómenos materiales y en nuestra investigación, estos autores, vienen a abrirnos nuevas posibilidades de comprensión; es así como un cuerpo, es entendido en tanto, acontecimiento, experiencia o potencia que hace presencia en la planta de producción. Estos cuerpos-potencia, son entonces, productores de unos saberes que se constituyen en su propia cotidianidad, son cuerpos que acontecen subjetivos y no cesan en su proceso de formación.

Entre las ideas que movilizaron esta investigación, destacamos el concepto cuerpo-máquina de guerra, el cual es planteado por Félix Guattari (DELEUZE; GUATTARI, 1972), teniendo como fuente las teorías psicoanalíticas, desde allí su noción de maquínica del inconsciente; a partir de aquí vuelca la mirada sobre los individuos y los grupos que tienden a funcionar como máquinas.

En Mil Mesetas (DELEUZE; GUATTARI, 2012), en compañía de Deleuze, avanzan ya, en el desarrollo del concepto de máquina de guerra, el cual es estudiado en el plano sociopolítico; la máquina de guerra, entonces, se ubica en las problemáticas propias de la vida social. Una las conclusiones interesantes que allí proponen que "un movimiento artístico, científico, 'ideológico', puede ser una máquina de guerra potencial, precisamente porque traza un plan de consistencia, una línea de fuga creadora, un espacio liso de desplazamiento, en relación con un filum" (DELEUZE; GUATTARI, 2012, p. 422, grifo do autor).

Así las cosas, el orden de la producción y de la institución escolar, irían en esa misma dirección; la planta de producción, una de las formas de materialización del sistema capitalista, constituye un espacio de confinamiento, en el cual se agencia un modo de vida y por supuesto, de un cuerpo al servicio de dicho sistema.

En este sentido, creemos importante forjar fisuras en esas corrientes discursivas altamente maquínicas, instauradas en la educación institucionalizada, vinculadas a la homogeneidad, al disciplinamiento, a la igualdad; lo bueno, lo verdadero y la reproducción que hacen parte de un sentido común que anulan la posibilidad de que algo nuevo surja, de que la diferencia en- 
cuentre un lugar y de que la fricción constante de la repetición deje entrever pequeños gestos creadores. Esa especie de extrañamiento desde lugares (otros) que permitieran percibir lo educativo de un cuerpo que se afecta y afecta en una planta de producción, nos convocó a considerar la manera misma de investigar; de allí, que nuestra experiencia cartográfica de una educación (otras), no se inscribió en una apuesta representativa de la realidad, y se resistió a concebir la experiencia en la planta de producción como un espacio para obtener información que luego pudiera ser interpretada en términos analíticos; por el contrario, hemos buscado generar movimientos que desafíen lo estático, lo perdurable en la educación de los cuerpos, a fin de ubicarnos y ubicar la investigación misma en el lugar de los acontecimientos, de las producciones subjetivas, de las afecciones de los cuerpos (de nuestros propios cuerpos), transitando la planta de producción.

De estos movimientos, de esas conexiones, se ocupó nuestra investigación cartográfica, en la que "justamente para poder pensar, dice Deleuze, hemos de descomponer el pensamiento ya fijado en una imagen, desplazando con ello su territorio de dominio" (BULO, 2009, p. 56), y dar así la posibilidad a la aparición de algo distinto en la experiencia de investigar. Es por esto que, nos cuestionamos la hegemonía de una educación, que se reduce a procesos de enseñanza-aprendizaje en el contexto de una institución y, por su puesto de una investigación que reproduce esquemas predefinidos; imposición y repetición de unos modos de saber y de unas maneras de proceder que, al parecer, no distan de las maneras de siglos atrás, en los que se privilegiaba el conocimiento intelectivo, en detrimento del acontecer de los cuerpos. En esta investigación, la cartografía se convirtió en el método que nos ha permitido mapear las fuerzas que surgieron del encuentro entre las posibilidades de una educación (otra), los cuerpos, la planta de producción y las diferencias que allí tienen lugar. En cuanto al modo de proceder, se hizo una apuesta por la experimentación, (HERNÁNDEZ; AGUIRRE, 2018), en la cual se dio cabida a las afecciones que corporales que circularon la cotidianidad de planta de producción.

Las experimentaciones que pusimos en acción, se interesaron por los tejidos que se fueron produciendo en los encuentros, en los entrecruzamientos e intercambios con las fuerzas, intensidades, afectaciones, velocidades y variaciones que acontecieron con los cuerpos y cómo estos produjeron diferencia; se trató entonces, de poner en presencia (GUMBRECHT, 2005) una percepción expandida, es decir, un cuerpo abierto a lo que acontece en ese momento. En esta experiencia de mapeo del acontecer de las(los) operarias(os), nos acompañamos de lo que Deleuze y Guattari (2012) nombran como afectos y perceptos, refiriéndose con ello, a unas maneras nuevas de ver, de sentir y escuchar la realidad y, por supuesto lo que sucede con nosotros mismos; a este respecto, indican: "de lo que siempre se trata es de liberar la vida allí donde está cautiva o de intentarlo en un incierto combate" (DELEUZE; GUATTARI, 2012, p. 173). Estas ideas, en torno de los afectos y perceptos, nos posibilitaron hacer visibles las fuerzas que fueron atravesando los encuentros, y desde allí nos posibilitó crear las acciones, las formas de registro y la emergencia de pensamientos que sustentaron la investigación; con ellos, con nuevos gestos y sensibilidades (acciones metódicas, modos de proceder), nos empeñamos en liberar la vida de los infinitos cautiverios que no dejamos de construirle.

En este orden de ideas, pusimos en marcha una mirada y una escucha deshabituadas, una percepción que perturbó la rutina e hizo visible las fuerzas presentes en los encuentros y que afectaron los cuerpos, al punto de hacer de cada encuentro, un encuentro singular. Estar en la planta de producción, no es un acontecimiento por sí mismo, sino que este fue producido por nuestra forma de mirar y escuchar; en términos de Farina (2005, p. 97), se trató de un "estado de alteración que experimenta un punto de vista afectado por las intensidades, y que en 
esa alteración le provocan - nuevos modos de sentir". Los movimientos que se provocaban en los encuentros con los trabajadores(as) de la planta y posteriormente entre nosotros mismos, incomodaban profundamente la representación habitual de la realidad, pues, abrir espacio a la potencia de los afectos, era permitir que estos nos alcanzaran, que trastocaran el hábito de nuestra condición sensible, de manera que los cuerpos de la experiencia de investigar crearan no solo, maneras nuevas de pensar, sino de existir.

\section{A propósito de este modo de investigar}

Ahora bien, los primeros acercamientos a la planta de producción, dejaron al descubierto la necesidad de configurar un método cartográfico propio, con el cual pudiéramos mapear el paisaje de una planta de producción, en la que se diseña, imprime y encuaderna material educativo; en este sentido, necesitábamos de un método que nos permitiera experimentar las multiplicidades de la experiencia de formación de los cuerpos, que nos distanciara de una eventual descripción etnográfica, y que nos abriera a la posibilidad de encontrar esos trazos sensibles cuando nos vemos forzados a hacer de lo cotidiano un paisaje geográfico y existencial:

Para los geógrafos, la cartografía, a diferencia del mapa, que es una representación de un todo estático, es un diseño que acompaña y se hace al mismo tiempo que los movimientos de transformación del paisaje. Los paisajes psicosociales son también cartografiables. La cartografía, en este caso, acompaña y se hace mientras se desintegran ciertos mundos, pierden su sentido, y se forman otros: mundos, que se crean para expresar afectos contemporáneos, en relación a los cuales los universos vigentes se tornan obsoletos. (ROLNIK, 1989, p. 2).

La cartografía se presenta, entonces, como una manera rizomática, sugerente para emprender procesos investigativos en el campo de la educación, pues, este va más allá de la definición de unas reglas o protocolos de investigación y elige un proceder que toma formas diversas. Se constituye a partir de líneas, no sólo una y recta que determina el camino, sino de una multiplicidad orgánica, que en nuestro caso tienen diferentes encuentros $\mathrm{y}$ despliegues a diferentes velocidades, con intensidades que varían y que hacen de los encuentros, siempre una construcción nueva, una configuración viva.

Cuando hablamos de cartografía hablamos de un proceso, de un caminar que es siempre diferente y que encuentra su trayecto de acuerdo con las problemáticas que son puestas en juego. En este sentido, hablamos de un proceder que no tiene reglas ni instrumentos de medición, sino que se compone de algunas pistas, líneas, atisbos que guían el trabajo investigativo y que constantemente van calibrado (KASTRUP; PASSOS, 2009). En este sentido una cartografía nunca será igual a otra, de allí, que nuestra experiencia cartográfica en la planta de producción estuvo marcada por situaciones variables y móviles, a partir de las cuales se fue recomponiendo el problema de la investigación, los conceptos, los modos de proceder y por supuesto los pensamientos que allí se compusieron. A este proceso, se refieren Oliveira y Mossi (2014, p. 196), al indicar que, "poderíamos, portanto, afirmar que, ao pesquisarmos algo, também estamos inventando aquilo que pesquisamos, e mais: inventando também a própria forma de pesquisar"; en este mismo sentido, para Suely Rolnik (1989, p. 185), las experiencias de lo educativo que circulan por esos paisajes de la planta, sería cartografiables, puesto que "para os geógrafos, a cartografia diferentemente do mapa, representação de um todo estático - é um desenho que acompanha e se faz ao mesmo tempo que os movimentos de transformação da paisagem".

En correspondencia, en la investigación Cartografías de una educación (otras), nos expusimos a la experiencia de invención-creación, de la cual se fue derivando la acción metódica 
denominada: Paisajear ${ }^{2}$, entramado de acciones $y$ afecciones dirigidas a componer paisajes existenciales, en el contexto de una planta de producción, comprendida esta, en tanto biósfera de la experiencia de educarnos y configurar esas formas subjetivas del transcurrir de la formación.

Paisajear, es entonces, una acción metódica que agenció una manera de cartografiar el acontecer de la formación - educación (otras) - en un ámbito no escolarizado, constituido por un conjunto de acciones-gestos, que no siempre comprendían actividades, de manera que las acciones del método, unas veces activaban formas de presencia y en otras, se tornaban acciones propiamente, que convocaban la expansión de los cuerpos, acentuaban la calidez de los encuentros, creaban conversaciones y ensayaban modos de estar juntos. ${ }^{3}$

Es así, que la experiencia con este método cartográfico en una planta de producción nos condujo a situar tres ejes de trabajo y composición de pensamientos, los mismos que desplegamos a continuación, a modo de resultados de la investigación.

\section{La planta de producción y la casa: espacios de producción corporal}

La planta de producción, los lugares de la casa y sus objetos se tornan espacios corporales, el cuerpo acontece en ellos, se despliega hasta borrar los límites de cada uno; los es-

2 Paisajear es una composición propia, que no corresponde a un término de uso reconocido en castellano; es un término que conserva la intención de dar vida a un entramado de acciones y afecciones en el contexto de la investigación Cartografías de una educación (otras). Paisajear, paisajeo, paisajeante, nos lleva a pensar en una serie de variaciones de orden verbal, tales como acciones de tiempo (paisajeo, paisajeé, paisajarearé); de voz (paisajea); de aspecto (he paisajeado, paisajeaba); de modo (paisajeas); de número (paisajeo, paisajeamos); y funciona también como gerundio (paisajeando), en ocasiones también como adjetivo (paisajeado).

3 El despliegue teórico, epistemológico y la configuración misma del método Paisajear, ha sido objeto de otra producción textual, de manera que no ahondaremos aquí en el tema. pacios de la casa o de la planta se extrañan de la misma manera que se extraña un miembro perdido. [Había vuelto a vivir en casa de mis padres, cuando conseguí este trabajo y con el salario de cada mes compraba pequeños lotes de ladrillos, de tejas e insumos, con el paso de los meses logré reunir los materiales con los cuales inicié la construcción del primer espacio, de una casita en un pequeño terreno cedido por mi padre]. Estos relatos, afloraron de muchas maneras, y exhibieron las corrientes subterráneas que circulan entre la planta de producción a la casa.

Lograr una vivienda propia, una casa-hogar, es una de las grandes ilusiones de los sectores populares en América Latina, [a la casa llego en las noches, me recuesto, subo los pies en una silla, y me quedo detenida, hasta que el reloj me hace levantar a preparar la cena y los alimentos - desayuno y almuerzo - que llevaré al trabajo al día siguiente], y se constituyen en un triunfo sobre las condiciones socio-culturales en las cuales se han desenvuelto. Algunas de las operarias de la planta de producción asocian y creen que el trabajo diario se materializa en su espacio propio; es claro que no hay una relación directa entre salario y obtención de una vivienda, en ello entran en juego un sinnúmero de variables, entre ellas el apoyo de otros familiares, una recia capacidad de ahorro, (lo que es más bien una actitud de privación que se asocia al sacrifico); $y$, por supuesto el endeudamiento a través de préstamos bancarios; razones por las cuales una casa propia es puesta en tan alta estima.

En esta casa-hogar, el cuerpo cansado entra en un estado de latencia y parece incubarse a sí mismo, al paso de las horas, se hace cada vez más líquido y, solo el sueño logra recomponerlo para hacerle frente a la siguiente jornada. Ubicamos en esta circulación de fuerzas que se arraigan en la trama espacial, planta de producción-casa, una subjetividad del lugar, donde ambos espacios más que una experiencia corporal en un espacio, pasan a constituirse en el cuerpo mismo. La planta de 
producción deviene casa, donde el cuerpo se condensa [recuperar fuerzas], para activar la operación del martes, del miércoles, del jueves, del viernes, del sábado y el ciclo recomienza de nuevo el lunes; Peter Sloterdijk (2012, p. 429), da una dimensión más amplia y envolvente a esta producción subjetiva,

Hablar de la Edad Moderna significa traer a colación la producción de un clima estimulante, que lo penetra todo, de elevación del rendimiento y despliegue de las capacidades, un clima que se había impuesto en los Estados absolutistas mucho antes de la proclamación social-darwinista de la competitividad como una ley presuntamente histórico-natural.

Ahora bien, la adquisición de una vivienda, un espacio propio, por parte de algunas operarias de la planta de producción, la encontramos, igualmente asociada a la construcción de una segunda capa de autonomía e independencia, pues la consecución de un trabajo formal y además estable, ya había construido una primera capa; al respecto de esta experiencia de satisfacción, escuchamos a mujeres, orgullosas de sobreponerse a aconteceres propios de su cotidianidad, de sus recorridos, de su estancia en la planta y en la casa; ellas, narraron con detalle la manera cómo su trabajo en la planta les posibilitó posicionarse en un universo social de una manera distinta y cobrar fuerzas para separarse de una relación de maltrato, por ejemplo. Así mismo, tomar fuerzas para reponerse de la muerte de un ser querido o echar mano de su experiencia de infancia maltratada, en la mayoría de los casos, para hacerse cargo y recomenzar una vida.

Notamos igualmente que, en la medida en que la planta de producción genera posibilidades, también demanda lo suyo y, en medio de la consolidación de estas capas de autonomía e independencia, - la planta -, se va instalando y cada vez reclama más espacio. [Pienso mucho en las vacaciones, pero después de dos o tres días sin venir a trabajar, la casa me quiere enloquecer]. De manera que está in-dependencia económica, constituye una experiencia subje- tiva que se va cociendo con hilos de colores comprados en la miscelánea del barrio para costurar los orificios que se van formando en los vestidos, en los uniformes que ordena la planta, más bien.

También nuestras labores diarias, en tanto profesores-investigadores, operan el régimen sensible en el que habitamos, esa industria de la producción académica de la que hacemos parte. La planta de producción y la industria académica, configuran una maquínica, una estructura económico-epistémica que agencia en tanto es agenciada; en este sentido los trabajadores de la planta, al igual que a nosotros, no hace falta que llevemos el trabajo a la casa; estamos en un régimen de producción que nos produce a nosotros mismos. Al respecto de este régimen de producción subjetiva incesante, Peter Sloterdijk (2012, p. 426), plantea que se trata de "una ascesis desespiritualizada se llama training y se corresponde con una forma de realidad que exige de los individuos, por decirlo así, fitness, fitness sans phrase". Este modo de producción crea objetos y subjetividades, que se reproducen de forma incansablemente.

\section{Los cuerpos de la planta de producción}

Las conversaciones con (las) (los) operarias(os) de la planta de producción, paisajearon para nosotros, no exactamente cuerpos industrializados como lo habíamos supuesto y que esperábamos correspondieran a las imágenes convencionales de los operarios de una fábrica, esto es, cuerpos que accionan las máquinas de una planta de producción. Al contrario, las imágenes corporales que vienen a nosotros, son cuerpos-máquinas, subjetividades bio-tecnológicas, donde el cuerpo y las máquinas, la planta misma y el sistema mismo de producción, constituyen un cuerpo (otro). Lazzarato (2007, p. 57), comentando una de las tesis de Guattari, indica que "hay máquinas que constituyen agenciamientos con el 
cuerpo del hombre o con partes [del cuerpo] del hombre". ${ }^{4}$ En este sentido, observamos que en la simbiosis cuerpo-máquinas se presentan en un proceso simultáneo de composición subjetiva, la máquina deviene cuerpo y este deviene máquina; en esta mutua circulación de agenciamientos, las máquinas se nutren de los cuerpos, a la vez que transmiten o mejor se dan a los cuerpos, se hacen cuerpos orgánicos a través de movimientos repetitivos que desarrollan músculos específicos; se hacen dolores crónicos, cicatrices y órganos perdidos.

En la relación con la máquina del proceso de producción industrial, se produce un cuerpo y en esa interacción cuerpo-máquina se configuran tonalidades de dolor. Cómo duelen los órganos. ¿Qué órganos duelen más? Duelen las piernas y los pies, dado que las jornadas laborales transcurren de pie. Duele el cansancio del cuerpo. Cuerpos cansados que duermen en los buses y en el metro, y es recurrente que se pasen de la estación de destino; al despertar se levantan silenciosos y retornan sin hacerse notar.

Las marcas de la Termoselladora sobre el cuerpo les dan formas a las cicatrices. Cicatrices del cansancio, del roce violento de los cuerpos con las máquinas. De lo que la máquina es capaz de hacerle al cuerpo, pues los accidentes ocurren cuando menos lo esperan. Simplemente pasa la máquina por el cuerpo, dejando su marca. Máquinas vivas, esas que tienen movimiento y en las que se prolonga la rutina, los movimientos repetitivos. Lazzarato (2007, p. 57, grifo do autor), continúa diciendo, que

[...] el registro llamado de producción maquínica o de servidumbre maquínica funciona sobre la base de semióticas a-significantes; aquí los signos no funcionan como significaciones sino como si fueran un operador material; en lugar de producir una significación, desencadenan una acción, una reacción, un comportamiento, una actitud, una postura.

El sistema de configuración subjetiva que la planta de producción agencia, y que sabemos

$4 \quad$ El paréntesis corresponde al texto citado. es agenciada a su vez por servidumbres maquínicas de mayor envergadura; por un lado, desbordan la jornada laboral, pues se trata de un régimen incesante; $y$, por otro lado, configura una semiótica de conducción precisa de desplazamientos, a la vivienda, [lugar de descanso del trabajo], al mercado [a comprar los alimentos para el consumo y llevar al trabajo $]^{5}$ y al centro médico por alguna dolencia propia o la de un familiar en primer grado; este guion de recorridos, rara vez es alterado, dado que especialmente las operarias -, lo asocian a una vida organizada o bien, debido al cansancio, que suponemos contribuye al adormecimientos de otros deseos. En conversaciones con algunas operarias de cierta edad, notábamos que el cumplimiento riguroso del guion de recorridos, estaba asociado a una identificación con los ideales de la buena madre o aquello de ser una "mujer de su casa".

El cuerpo constituido en el contexto de la planta de producción, dibuja un cuerpo cansado, sujetado a un campo de producción de sensibilidades económicas, que se enraízan en un circuito de afectos; en las conversaciones con las operarias, principalmente, no se escatiman palabras de agradecimiento a los propietarios de la planta, los listados de pequeños beneficios son interminables, [con este trabajo he levantado a mis hijos, puedo comer todos los días, tengo servicio médico, conocí el mar], las narraciones que escuchamos dicen casi nada de relaciones contractuales, pues lo que circula en ellas, son las tonalidades de vínculos construidos en una red sensible de gratitudes, asociadas en muchos casos a favores divinos.

Notamos que la extensión de esas gratitudes - devoción, a veces - está en correspondencia con las dificultades afrontadas con antelación a la consecución del empleo en la planta de producción o bien al tiempo de estar cesante laboralmente. Esta "oportunidad laboral", como es nombrado el trabajo en la planta,

5 Los trabajadores de la planta traen de sus casas el desayuno, el almuerzo y dos meriendas, solo ocasionalmente compran en la planta misma o alrededor algún alimento. 
agencia diversidad de pliegues de dedicación y compromiso que se traducen en cuerpos comprensivos y dispuestos, es decir, cuerpos sumisos y obedientes, cuerpos de mujeres, en su mayoría.

Esta preferencia por contratar mujeres no es casual, pues se corresponde con un discurso social, consolidado en las tres últimas décadas; en la Constitución colombiana de 1991, se puede leer en su Artículo 43, que "El Estado apoyará de manera especial a la mujer cabeza de familia" (COLOMBIA, 1991). En este mismo sentido, en una sentencia de la Corte Constitucional, se dice entre otras cosas, lo siguiente:

[...] uno de los roles que culturalmente se impuso a la mujer fue el de "encargada del hogar" como una consecuencia del ser "madre", de tal suerte que era educada y formada para desempeñar las tareas del hogar, encargarse de los hijos y velar por aquellas personas dependientes, como los ancianos. Sin desconocer la importancia que juega toda mujer, al igual que todo hombre, dentro de su hogar, el constituyente de 1991 quiso equilibrar las cargas al interior de la familia, tanto en las relaciones de poder intrafamiliar, como en cuanto a los deberes y las obligaciones de las que cada uno es titular. Suponer que el hecho de la 'maternidad' implica que la mujer debe desempeñar ciertas funciones en la familia, ha llevado, por ejemplo, a que tengan que soportar dobles jornadas laborales: una durante el día como cualquier otro trabajador y otra en la noche y en sus ratos libres, desempeñando las labores propias de la vida doméstica. Esta imagen cultural respecto a cuál es el papel que debe desempeñar la mujer dentro de la familia y a cuál 'no' es el papel del hombre respecto de los hijos, sumada al incremento de separaciones, así como al número creciente de familias sin padre por cuenta del conflicto armado y la violencia generalizada, trajo como consecuencia que una cantidad considerable de grupos familiares tuvieran una mujer como cabeza del mismo. (COLOMBIA, 2003).

Este discurso legislativo y socio-académico, ha tenido simultáneamente un importante despliegue en los medios de comunicación masiva, de manera que se ha afianzado una discursividad socio-cultural que asegura, entre otras cosas, que las mujeres cabeza de familia son más responsables y dedicadas a su trabajo; por su parte sectores empresariales, ostentando su sentido de responsabilidad social, han capitalizado esa condición descrita por la Sentencia de la Corte Constitucional, en función de asegurarse una población trabajadora de cuerpos metódicamente seleccionados y clasificados.

Observamos, entonces, cómo una condición socio-contextual configura un mecanismo que clasifica, segrega, conduce y vincula de manera eficiente un grupo poblacional al aparato productivo; pues, cuando este sistema se dispone a poner en funcionamiento empresas en las que solo se contratan mujeres y preferiblemente mujeres cabeza de familia, están interesadas justamente, en aquello en lo que estas mujeres son altamente eficientes, "tener bajo su cargo"6 es decir, cuidar con abnegación; es claro, que en cierta medida lo que se busca capitalizar es un modo de estar en el mundo, una producción subjetiva y, no una competencia laboral de orden profesional. Nos sobrevienen aquí preguntas que no se hacen esperar ¿qué afectos circulan por una planta de producción o por una cadena de restaurantes donde solo se emplean mujeres? ¿Cómo mapear la capitalización de afectos en la segregación social de modo que puedan ser audibles y visibles?

En todo esto, se cruzan múltiples intensidades, entre ellas construcción cultural de redes de afectos; las subjetividades de derecho ${ }^{7}$ y sus correspondientes despliegues en los diversos contextos sociales. Volverse mujer cabeza de familia, configura una condición subjetiva que agencia diversidad de marcas en el territorio existencial, un cuerpo sumiso y obediente en

6 La Sentencia c-184 de la Corte Constitucional, expresa en su concepto que es, "Mujer cabeza de familia, quien, siendo soltera o casada, tenga bajo su cargo, económica o socialmente, en forma permanente, hijos menores propios u otras personas incapaces o incapacitadas para trabajar, ya sea por ausencia permanente o incapacidad física, sensorial, síquica o moral del cónyuge o compañero permanente o deficiencia sustancial de los demás miembros del núcleo familiar"

7 Aludimos a un proceso de producción subjetiva en el cual el lenguaje normativo es su principal recurso simbólico. 
el plano laboral y, complaciente y sacrificado en el plano familiar; Gloria María Bustamante (BUSTAMANTE; HENAO, 2016, p. 3) indican en una de sus investigaciones que "la cultura es el primer depredador de las mujeres encarnado en el núcleo familiar, el padre, el esposo y, algunas veces, en los hijos. Se nace niña y ya están actuando las fuerzas del patriarcado sobre lo que será su destino".

Lo que observamos en todo esto, son esas refinadas acciones maquínicas, a través de las cuales los regímenes político-económico, en coalición con el Estado, quien ya no opera la máquina de guerra, pero acciona mecanismos legislativos, a través de los cuales ciertas condiciones sociales de la población se tornan afectos, es decir, formas de exterioridad que "atraviesan el cuerpo como flechas, son armas de guerra” (DELEUZE; GUATTARI, 2012, p. 363); en consecuencia, en sofisticados mecanismos aseguran una población altamente obediente y laboralmente eficiente.

Los cuerpos en la planta de producción, entonces, aparecen en constante tensión: entre la maquínica socio-cultural que las envuelve en sus redes de aspiraciones y la planta en tanto empresa, con su orden de razones, jerarquías, normas; tensiones en las que prevalece el cumplimiento de la norma, antes que permitirse alguna flexibilidad y quedar por fuera la producción, del orden existencial que agencia.

\section{Las experiencias vitales configuran un acontecimiento que agencia la formación}

En las conversaciones con las operarias y operarios de la planta de producción, casi siempre estuvo presente y de manera insistente una voz (otra); esta adquirió un carácter fantasmal, que parece estar construida con retazos de recuerdos difíciles de situar en el despliegue de sus propias vidas, pues, parecen provenir de un territorio discursivo familiar, padres, madres o abuelas y, ancestral-cultural, ya este no se circunscribe de forma exclusiva a un tronco familiar único, sino que se escucha en la voz de otras, con la misma convicción. Estas voces a las que nos referimos, circulan en forma de consignas, [toca mirar siempre para adelante], modos de proceder [lo que una no haga por sí misma nadie lo va a hacer], y a veces sentencias [a una le toca hacer lo que sea por sacar adelante a sus hijos], [eché mano de lo poco que tenía y me abrí camino desde muy niña, todo por salir adelante].

Esta voz (otra), aparece asociada a una experiencia crucial, otras veces se presenta articulada a la historia de lucha y tenacidad de alguna figura parental, de manera que se instala en el cuerpo en tanto acontecimiento (performativo), y desde ese lugar existencial, se provee de cierta manera un tránsito más o menos seguro por la existencia; notamos además, que a través del conocimiento que allí se condensa, las mujeres de forma particular, alientan para sí mismas y para las personas con las que conversan, una ética del cuidado y protección del otro y de la familia.

Observamos que, en algunas(os), ese acontecimiento al que nos referimos, se compone a gestos o decisiones de sus padres, por ejemplo, el matrimonio estable de los padres se convierte en referente, no para ser repetido, sino que ese compromiso de vida solidaria, parece ser el aliento para sortear las adversidades propias, [abandonar a un marido agresor; superar la muerte de un hijo]. Esta imagen-gesto, actúa también como un referente de vida para sustentar con cierta delicadeza las determinaciones que se van tomando. [Optar por separación de cuerpos y al cabo de un par de años, decidir la separación del espacio de convivencia].

En otras operarias y operarios este acontecimiento, que agencia la formación tiene un tono mucho más intenso y a veces dramático, [la amenaza de un grupo paramilitar; escapar a la muerte en un tiroteo del barrio; ver morir a los amigos del colegio o del pueblo; ser entregado a la policía por parte de la madre y luego ser recluido en un internado; dejar for- 
zadamente el pueblo]; dicho acontecimiento se convierte en referente para la existencia y es marcado como un punto que posibilita una lectura de vida, en términos de un antes y un después. A este acontecimiento le asignamos un carácter fantasmal, pues, observamos que la manera como se establece es incierta o bien es la sumatoria de eventos ocurridos en diferentes momentos de la vida, pero esto, al final carece de importancia, pues lo que notamos interesante es la manera como observamos que ese acontecimiento agencia su propia constitución subjetiva.

El acontecimiento hace un trabajo en el cuerpo, se instala subjetivamente, con ello queremos indicar que no se trata de una lección aprendida de un suceso vital; pues a la trama que sustenta a tal acontecimiento, se le asigna un compromiso propiamente existencial, [a partir de ahí], por ello posee esa fuerza de referente que marca y conduce el curso de las decisiones posteriores.

En este sentido, la formación, tendría que ver con la elección de las maneras de afectar y afectarse de los cuerpos, para Farina (2005), tendría que ver con las formas de ofrecer superficie de desliz sobre lo normalizado en el contacto, para la constitución de una actitud sensible y cognoscente que no está, pues formación es una cuestión de actitud, de un proceder con el pueblo existente, con el pueblo que está, porque todo empieza en presencia del pueblo que existe.

\section{Feminidades masculinizadas}

En esta planta de producción, entre las operarias(os) con quienes conversamos, nos encontramos, particularmente, con un grupo de mujeres mayores, que llevan entre 15 y 20 años laborando de manera continua en este lugar. Algunas de ellas nos dejaron saber que en ciertos momentos de sus vidas fueron condescendientes con el maltrato por parte de sus parejas a fin de conservar el apoyo económico y dar bienestar a sus hijos; pero que una vez pudieron acceder a un trabajo propio, abandonaron sus parejas y optaron por no volver a construir este tipo de vínculos; notamos que se ubican en el lugar de una figura patriarcal ejemplarizante de manera que los vínculos afectivo-sexuales parecen perder importancia. A este respecto la investigadora Gloria Amparo Henao (HENAO; GÓMEZ, 2008), considera que la masculinización de la feminidad está en relación con una afirmación de autonomía y defensa de los lugares que las mujeres logran conquistar; en su investigación Por el derecho al sueño, indica que, "el hecho de provenir de un mismo sector y el sentido de ser grupo les confiere seguridad y poder, que usan de un modo masculinizado" (HENAO; GÓMEZ, 2008, p. 67).

Observamos la organización de redes de relaciones afectivas y de convivencia que subvierten el modelo nuclear de familia, formada por la madre, el padre y los hijos, para dar lugar a otras formas de procurarse afectos mutuos, [ex-esposos y parejas actuales que cooperan y comparte la cotidianidad de la familia]; invención de nuevas estructuras afectivo-familiares [una madre con sus dos hijas, quienes parecen no tener interés en conformar relaciones de pareja y tampoco en ser madres]. Estas feminidades masculinizadas que parecen no necesitar de otros sexos también ejercen su poder en la planta de producción, se distinguen por su fuerza física, operar las máquinas de mayor riesgo y habilidades para formar a los nuevos operarios.

Es claro que acceder a un trabajo en una planta de producción, que brinda continuidad y reconocimiento a la labor que se desempeña, agencia transformaciones significativas en las maneras de constituir sus propias subjetivadas; en particular, este grupo de mujeres que pasan el día juntas y que ponen en circulación sus historias de vida, las intimidades familiares y sus perspectivas de la existencia; consideramos que, al transcurrir el tiempo van construyendo un pensamiento colectivo en torno de lo femenino, en los que aparecen distantes de los modelos convencionales de mujer sumisa que 
cuida de los hijos y se ocupa de las actividades del hogar y, por supuesto, más distantes aun, de las figuras hetero-masculinas, de las cuales parecen tener noticias a través de las historias de sufrimiento de otras mujeres. Nos encontramos, entonces, con unas nociones de lo femenino construidas a partir de imágenes no deseadas de lo hetero-masculino, figuras de las que en momentos clave, han tenido que escapar [un marido agresor o un grupo armado].

\section{A modo de conclusiones}

La investigación Cartografías de una educación (otras), nos posibilitó la inmersión, intervención y experimentación-creación, en el contexto de una planta de producción de materiales educativos, a partir de un método cartográfico que puso en circulación intensidades que nos forzaron a pensar las maneras como se configura lo educativo por fuera de la institucionalidad escolar. Es esta investigación, el cuerpo estuvo en primer plano, un cuerpo sobre el que volvemos una y otra vez, en tanto lente teórico-epistemológico, que se torna, escucha atenta, percepción de los movimientos del paisaje, afecciones que forman modos de acontecer. Cartografiamos en este lugar los intersticios de las palabras, de los cuerpos, de los sentidos que habitan una planta que además de su actividad económica, produce subjetividades y formas de lo femenino. Mientras tanto, los investigadores nos pusimos en presencia en ese paisaje industrial, con una mirada y una escucha que acompañaba y valoraba esos gestos-acciones que educan, en tanto son modos de existir.

En este sentido, la cartografía nos alentó a transitar unas formas de presencia a través de las cuales experimentamos la investigación, de manera que esta se fue haciendo posibilidad de inmersión en el plano de la experiencia, en las experiencias de las operarias y los operarios de la planta de producción, no para crear un reverso de la educación o de lo que dice la educación de los cuerpos en el universo laboral, sino para ocuparnos de esas maneras (otras) en que los cuerpos, sus afecciones, se constituyen en el permanecer, moverse y transitar por y desde la planta hacia otros lugares de la ciudad.

La planta de producción, por su parte, aparece articulada a ese régimen de producción económico-político que agencia de forma incesante la vida, la ocupación del tiempo y que, determina los recorridos por la ciudad. Los toques, los roces que se producen en el existir, también habitaron estos espacios que, a su vez, transitan y mutan; aquí, el cuerpo inventa intensidades que rompen las inhibiciones que producen los entornos educativos institucionalizados. Observamos unas subjetividades que se constituyen en el fluir, que se resisten a asumir identidades convencionales, que valoran los saberes y sensibilidades construidos en el interior de esta institución, que es también de encierro. La planta, la casa y sus objetos se tornan espacios corporales, el cuerpo se encarna, forma uno con estos, de allí que se les extrañe como un miembro perdido. Esta experiencia de corporeización del espacio es lo que optamos por denominar subjetividad del lugar.

En el contexto de esta planta de producción, lo educativo aparece conectado a la experiencia sensible de producirse a partir de esos acontecimientos que se presentan de forma inusitada $\mathrm{y}$, que vienen a agenciar de forma sucesiva en el tiempo, las experiencias vitales; así mismo, percibimos que en los relatos de vida que allí circulan, está presente de manera insistente una voz-otra, formada por retazos de recuerdos familiares, consignas respecto a maneras adecuadas de comportarse, las misma, que a veces adquieren un tono de sentencias; notamos, que esta voz parece actuar como un contenedor (caparazón) que asegura de cierta manera la experiencia de existir.

Encontramos también, que la educación (otras) está vinculada a la construcción de una subjetividad que se teje a partir de un acontecimiento intenso que hace posible dar giros a la existencia y que, es marcado con 
ciertas palabras: amenaza de un grupo armado; miedo a perder la vida; dolor por una pérdida; autonomía económica, entre otras. Este acontecimiento, produce invenciones para lidiar con las experiencias de dolor: muertes violentas que cambian la vida, confrontan y obligan a potenciar fuerzas para continuar viviendo. Observamos que junto a un gran dolor o el aguantar hambre, se va superponiendo una capa sutil que, espera el momento indicado para impulsar a una nueva vida y crear formas auténticas (propias), de sobreponerse a las adversidades; de manera, que la formación se ve agenciada por acontecimientos que fijan sus raíces en el cuerpo, pues en él acontece y, entran a circular por la cotidianidad compartida; esto nos condujo a pensar en las posibilidades de aprendizaje que se anudan en torno del acontecimiento.

\section{REFERENCIAS}

BULO, V. Cuerpo y diferencia en Gilles Deleuze. Revista internacional de Filosofía, n. 48, p. 5563, 2009.

BUSTAMANTE, G.; HENAO, G. Voces y silencios, una investigación comprensiva desde las narrativas de las mujeres. Medellín: Corporación Educativa Combos, 2016.

COLOMBIA. Constitución Política de Colombia. Bogotá, 1991. Disponible en: http://www.secretariasenado.gov.co/index.php/constitucion-politica. Acceso en: 22 nov. 2018.

COLOMBIA. Corte Constitucional. Sentencia c-184, de 04 de marzo de 2003. Bogotá, 2003. Disponible en: http://www.corteconstitucional.gov.co/relatoria/2003/C-184-03.htm. Acceso en: 22 nov. 2018.

DE CERTEAU, M. La invención de lo cotidiano. I Artes de hacer. Primera reimpresión. México D.F: Universidad Iberoamericana/Instituto Tecnológico y de Estudios Superiores de Occidente, 2000.

DELEUZE, G.; GUATTARI, F. Mil mesetas. Capitalismo y esquizofrenia. Valencia: Pre-Textos, 2012.

DELEUZE, G.; GUATTARI, F. L'Anti-Oedipe. Capitalisme et schizophrénie. Paris: Les Éditions de Minuit, 1972.
FARINA, C. Arte, cuerpo y subjetividad. Estética de la formación y Pedagogía de las afecciones. 2005. Tesis Doctoral. Universidad de Barcelona. Barcelona, 2005. Disponible en: http://diposit. ub.edu/dspace/handle/2445/43042. Acceso en: 12 mar. 2018.

FOUCAULT, M. Vigilar y castigar. Nacimiento de la prisión. México: Editorial Siglo XXI, 2002.

GUMBRECHT, H. Producción de presencia: lo que el significado no puede transmitir. México: Universidad Iberoamericana, 2005.

HENAO, G.; GÓMEZ, S. Por el derecho al sueño. Medellín: Corporación Educativa Combos, 2008.

HERNANDEZ, E.; AGUIRRE, Y. Intensidades del olvido: experimentación-creación de imágenes en entrecruces con el pensamiento de Henri Bergson. Tsantsa: Revista de Investigaciones Artísticas, n. 6, 2018.

KASTRUP, V.; PASSOS, E. Cartografar e acompanhar processos. En: PASSOS, E.; KASTRUP, V.; ESCÓSSIA, L. Pistas do método cartográfico: pesquisa-intervenção e produção de subjetividade. Porto Alegre: Sulina, 2009. p. 52-75.

LAZZARATO, M. La filosofía de la diferencia y el pensamiento menor. Bogotá: Editorial Universidad Central/Fundación Comunidad, 2007.

NIETZSCHE, F. Ecce Homo. Cómo se llega a ser lo que se es. Cuarta reimpresión actualizada. Madrid: Alianza Editorial, 2017.

OLIVEIRA, M.; MOSSI, C. Cartografia como estratégia metodológica: inflexões para pesquisas em educação. Conjectura: Filosofia e Educação, Caxias do Sul, v. 19, n. 3, p. 185-198, set./dez. 2014.

SANDERS, O. Guattari's pedagogies as a theory of 'Bildung': becoming-pedagogue and the concept of a new school. Policy Futures in Education, Oxford, v. 9, n. 4, p. 454-464, 2011.

SLOTERDIJK, P. Has de cambiar tu vida. Traducción: Pedro Madrigal. Valencia: Editorial Pre-Textos, 2012.

ROLNIK, S. Cartografia sentimental: transformações contemporâneas do desejo. São Paulo: Estação Liberdade, 1989.

Recebido em: 01/06/2019 Aprovado em: 02/12/2019 